\title{
An Improvement of Content and Teaching Methods for Codes of Conduct and Ethics in Mass Communication Courses of Thailand's Universities
}

\author{
Wilailuck Suvachittanont \\ Ramkhamhaeng University, Bangkok, Thailand \\ wila37@yahoo.com
}

\begin{abstract}
This research examines the content about ethical issues in Thailand's mass communication courses, teaching methods and guidelines for improving the content and teaching methods about codes of conduct cultivation. This research uses 3 methods in collecting data: content analysis of syllabus in mass communication courses, focus group of experts and in-depth interviews of instructors and professionals. The results show that most media courses emphasize every-day life and professional ethics. Their main content focuses on principles law and ethics which are taught by lecture in classes without any professional organizations' collaboration. Most instructors and students do not aware of the significance of mass communication ethics' courses. Guidelines for improving content and teaching methods which suggested by experts and instructors are: 1) collaborating of third parties-mass communication/professional organizations, institutions and enterprises 2) emphasizing practices in reallife situations/scenarios and discussions 3) training and adjusting instructors' attitudes toward mass communication's ethics including a role model 4) updating ethical courses' content and interposing it in every course.
\end{abstract}

Keywords: Code of conduct, ethics, teaching and learning and mass communication course

\section{Introduction}

Media play an important role in cultivating and protecting society's ethics via unveiling the fact, truth and knowledge to the public. Media reflect the truth openly which affect on individual, group and state authority. In the mean time, media are part of social problems such as causing of conflict and violence. This is because media are under the market mechanisms which focus on audience's curiosity for advertizing and popularity competition without concerning of the negative impact on public interest in the long term. Additionally, the public criticize media conducts, especially pornography publishing or broadcasting. Hence, the public question about the media's ethics. However, media argue about this criticism by raising the freedom of expressing and writing. When media are treated by law and order, they often claim it as a threat (Subhunthad, 2009). Ethics violation of media in Thailand is available in many forms such as receiving bribe, privacy/human rights abuse and news report distortion, etc. Moreover, news reporting and comments often control by advertisers. These are the problems of media works which affect societies and country development because they don't do their job. This is a challenge of media works in these days to prove that they are the professionals and maintain their indignity as the fourth state of the society. Therefore, the media in Thailand need to improve and cultivate the ethics to their staff and people who are going to be journalists, especially the institutes and universities which produce media professionals.

The media professional development is one of the Council Press of Thailand's important functions. As the professional organization, the Council Press is the first media organization to have the codes of conduct after the self -regulation using did not work well. This is because most journalists think that they should not check themselves. It was not their duty. However, the Council press of Thailand cannot control or take care of all media regarding of a high competition in business. In this sense, the cultivation of ethics and codes of conduct should not depend on only the media professional organizations. It should be the corporation of educational institutes and media organizations to promote the awareness of media ethics especially, in the universities. Thongpao, a Thai famous journalist (2009) suggested that the significant ways to cultivate the media ethical aspects and practices to the journalists are to improve the content of ethical and related courses and the management of learning in the class. Among the variety of media platform today, the problems of the media ethics and codes of conduct in Thailand are increasing and becoming a hot issue in Thai society. It is also a responsibility of Thailand's educational institutes/universities to explore the ways of teaching and learning for supporting a better quality of media professional. 


\section{Methodology}

This research used qualitative approach in order to collect primary and secondary data. Primary data are collected from 1) 75 curriculums and 20 course syllabi of media ethics and related subjects which are available in bachelor degree of Thailand's universities and 2) in-depth interviews and focus group. Secondary data are collected from documents, books, texts and the internet. Key informants are selected purposively in the area of mass communication. They are 5 people who are instructors and professionals in journalism for focus group or group interview and 10 people for in-depth interviews. All key informants have experienced in mass media academic and professional at least years. Data collection from key informants, curriculums and course syllabi are analyzed by content analysis which employed interpretation, instant comparison, synthesis and generalization.

\section{Results and Discussion}

In the content analysis of curriculums and course syllabi of media ethics and related subjects, the result shows that most of mass communication curriculums provide and emphasize both basic media ethics and codes of conducts. They aim to cultivate public awareness and develop students or learners to be opinion leaders. The content of course syllabi of media ethics and related subjects comprises of principles, media law, ethics and codes of conduct. In the focus group of mass media experts, the result shows that most ethics and codes of conduct classes in Thailand's universities focus on only lecture. The instructors and students do not aware of the significance of this kind of subject. The lectures do not relate to the law and mass media context. Most media professionals do not pay attention to the ethics and codes of conduct violation increasingly. The increasing of hours in media ethics and codes of conduct teaching classes are limited by the amount of subject credits. There is less collaboration between universities and media organizations. An improving of media ethics and codes of conduct classes should use mixed method teaching by brainstorming both professionals and lecturers in universities to set up a standard curriculum and course syllabus as a model. Meanwhile, lecturers can develop it for their own experiences and context.

In the in-depth interview of 10 lecturers and professionals, most of them stated that:

- Most cases that people who work in mass media organizations violated ethics and codes of conduct came from a high competition in media businesses and a lack of ethical consciousness or media responsibility.

- A problem of teaching media ethics courses came from instructors and teaching method or technique. Most instructors did not pay attention in the significance of media ethics and codes of conduct. They were not a role model and often have fixed ideas, did not raise the cases which linked to the lesson. Also, most of them used only lectures without discussions.

- Several media professional institutions in Thailand should join together and collaborate with academics institutions or businesses in order to develop a qualified seminar or workshop about media ethics and codes of conduct. The professional institutions should give the rewards and compliments to the journalists who are keeping the codes of conduct. In the same way, journalists who violate code of conduct and ethical issues should be punished according to the rules and orders.

- A guideline for improving teaching class should focus on 4 main points: 1) making a network between professional organizations and academic institutions/media business. 2) Focusing on practical parts in order to influence students to learn from case study, discussion, situation and phenomenon. 3) Developing instructors to have a positive attitude towards media ethics and codes of conduct. Meanwhile, instructors would become a role model for students. 4) Always updating the content of the media ethics and inserting the media ethics content in every course.

Regarding the result of the in-depth interview about professional institutions should give the rewards and compliments to the journalists who are keeping the codes of conduct. In the same way, journalists who violate code of conduct and ethical issues should be punished according to the rules and orders. This is relevant to Chitdamrongchai's result (2003) and Virawongchai's result (2006). Chitdamrongchai found that the protection of codes of conduct violation can be successful by promoting engineers to participate in the ethics training session. It is the same as engineering professional codes of conduct. While 
Virawongchai suggested that journalists who violated the codes of conduct should be punished by the The National Council Press of Thailand. Due to the result about the method of teaching by letting students learn from the real situation and model of situation will encourage students to be interested and pay attention on media ethics and codes of conducts, it is relevant to Wattana's result (2001) and Kohlberg's moral development theory (Kohlberg in Crain, 1985). Wattana found that academic achievement of students who learned from ethic model was higher than the other groups significantly including learning discipline and ethical thinking. This finding can be explained by the Kohlberg's moral development. Kohlberg's theory of moral development suggested six stages within three different levels. Kohlberg extended Piaget's theory, proposing that moral development is a continual process that occurs throughout the lifespan. The six stages are 1) obedience and Punishment 2) Individualism and Exchange 3) Interpersonal Relationships 4) maintaining social Order 5) social contract and individual rights and 6) universal principles.

\section{Conclusion}

The content analysis of curriculums, course syllabi, focus group and in-depth interviews of key informants can be concluded as Figure 1

\section{Figure 1: A development of guidelines for improving content and teaching methods}

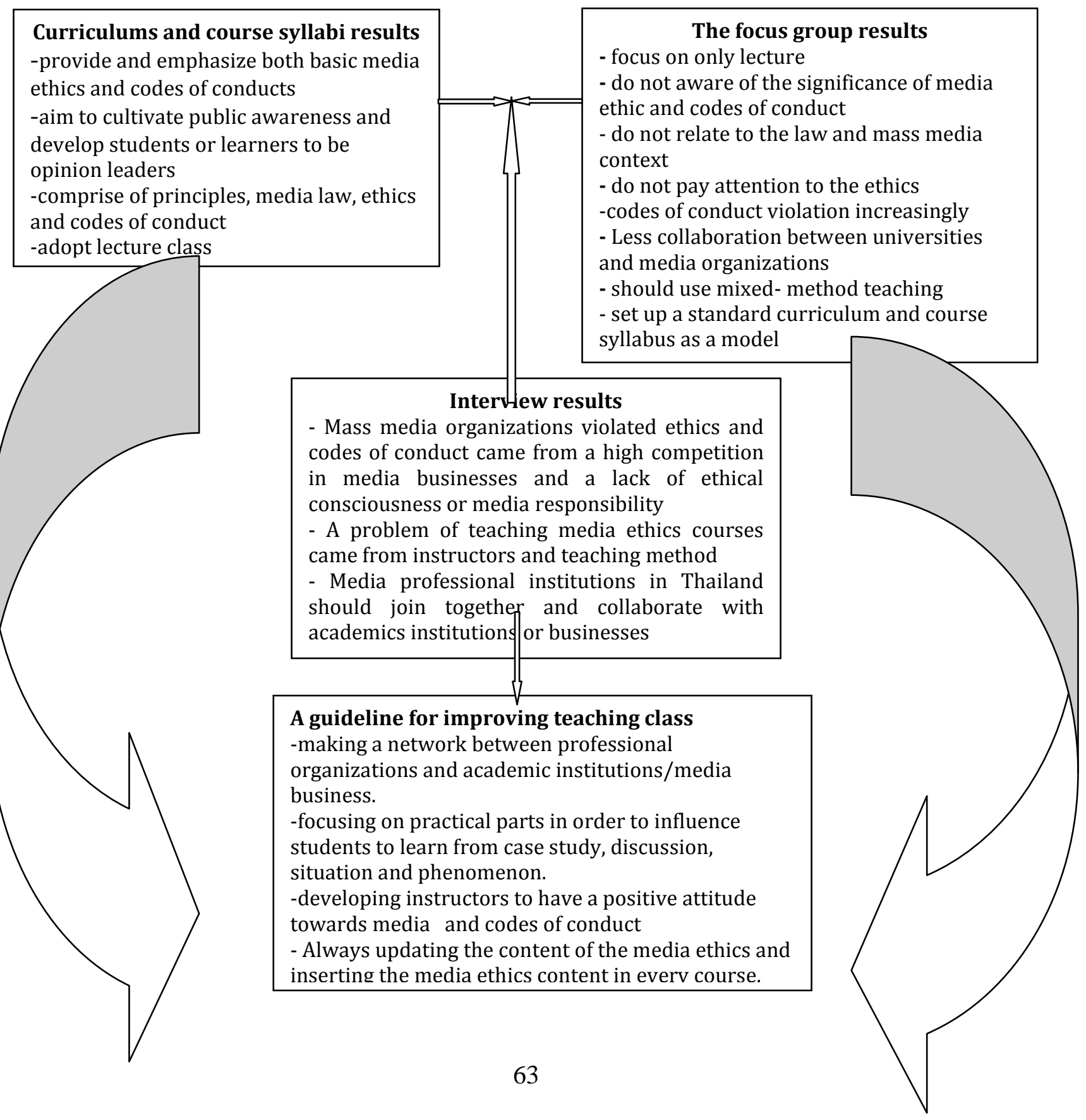




\section{Recommendations}

- Acknowledge and train instructors to have a negative attitude towards media ethics and codes of conducts including promoting them to be a role model of keeping ethical practices.

- Improve teaching technique by adopting mixed-method and emphasize discussion and practices.

- Update the content of the content of the media ethics and putting the media ethics content in every course for cultivating students' awareness.

- Support good network between media professional organizations, academic institution and media corporations continually

\section{References}

Chitdamrongchai, C. (2003). Engineering Ethics. Master thesis in Ethical Studies. Nakhonpathom: Mahidol University.

Crain, W. C. (1985). Theories of Development. N.J. Prentice-Hall.

Subhunthad, S. (2009). Media Ethics. Thai post Newspaper (April, 26 2009) online. Retrieved March 26, 2010 from http://www.thaipost.net.

Thongpao, T. (2009). State and Thai Media during Political Changes. Bangkok: The National Council Press of Thailand.

Virawongchai, N. (2009). Knowledge and Opinions of Thai Journalists on self-regulation under The National Council Press of Thailand. Master Thesis in Communication Arts. Bangkok: Chulalongkorn University.

Wattana, J. (2001). A Development of Ethic model Cultivation. Kasetsart University Academic Conference Proceeding on February 5-7, 2001. pp. 294-300. 